\title{
Robust Spatial Durbin Model (RSDM) untuk Pemodelan Tingkat Pengangguran Terbuka (TPT) di Provinsi Jawa Barat
}

\section{Hanna Nurul Khofifah*}

Prodi Statistika, Fakultas Matematika dan Ilmu Pengetahuan Alam, Universitas Islam Bandung, Indonesia.

*hannanurulk@gmail.com

\begin{abstract}
Spatial regression is used to determine the relationship between the response variable and predictor variables that have a spatial influence in it. If the response variables and predictor variables have a spatial effect, then the model formed is the Spatial Durbin Model (SDM). Outliers in spatial data are often found when conducting the research. Robust Regression is generally used to overcome outliers. Robust regression used in spatial data is a combination of the SDM methods and Robust regression, thus it form a method called Robust Spatial Durbin Model (RSDM). The estimation method used is the Maximum Likelihood type estimation (M-estimator), with expectation that it could accomodate the existence of outliers in the spatial regression model. In this study the response variable is the Open Unemployment Rate, and the predictor variable is the Human Development Indeks, District/City Minimum Wage, Dependency Ratio. Labor Force Participation Rate, education level, and number of poor population. From the results of the study the value Adjusted R2 0,9850 which means $98,5 \%$ TPT is influenced by the variables in the model. It means that RSDM is a good model to explain TPT in West Java Province.
\end{abstract}

Keywords: Maximum Likelihood type estimation, Outliers, Robust Spatial Durbin Model, Spatial Durbin Model, Spatial regression.

Abstrak. Regresi spasial digunakan untuk mengetahui hubungan antara variabel respon dan variabel prediktor yang memiliki pengaruh spasial di dalamnya. Jika dalam variabel respon dan variabel prediktor mempunyai pengaruh spasial, maka model yang dibentuk yaitu Spatial Durbin Model (SDM). Pencilan pada data spasial sering ditemukan ketika melakukan penelitian. Secara umum metode yang dapat digunakan untuk mengatasi pencilan yaitu regresi robust. Regresi robust yang digunakan pada data spasial merupakan kombinasi dari metode SDM dan Regresi robust sehingga membentuk suatu metode yang disebut Robust Spatial Durbin Model (RSDM). Metode estimasi yang digunakan yaitu estimasi Maximum Likelihood type (M-estimator), dengan harapan dapat mengakomodasi keberadaan pencilan dalam model regresi spasial. Pada penelitian ini variabel respon adalah Tingkat Pengangguran Terbuka (TPT) dan variabel prediktor adalah Indeks Pembangunan Manusia (IPM), Upah Minimum Kabupaten/Kota (UMK), Rasio Ketergantungan, Tingkat Partisipasi Angkatan Kerja (TPAK), Tingkat Pendidikan, dan Jumlah Penduduk Miskin. Dari hasil penelitian diperoleh nilai Adjusted R2 sebesar 0,9850 yaitu 98,5\% TPT dipengaruhi variabel yang ada didalam model. Hal ini menunjukkan RSDM merupakan model yang baik untuk menjelaskan TPT di Provinsi Jawa Barat.

Kata Kunci: Estimasi Maximum Likelihood type, Pencilan, Regresi Spasial, Robust Spatial Durbin Model, Spatial Durbin Model. 


\section{A. Pendahuluan}

Analisis regresi merupakan suatu metode statistik yang digunakan untuk memprediksi variabel respon jika variabel prediktor diketahui. Akan tetapi, dalam beberapa kasus penelitian sering ditemukan data yang memiliki efek spasial (lokasi) atau disebut data spasial. Ditemukannya efek spasial pada data penelitian karena adanya pengaruh antara suatu lokasi dengan lokasi lainnya yang saling berdekatan. Oleh karena itu, model regresi spasial dikembangkan untuk menganalisis data spasial (Hakim et al., 2019).

Salah satu dari model regresi spasial adalah Spatial Durbin Model (SDM), yaitu suatu model regresi yang memiliki pengaruh lag spasial pada variabel respon maupun prediktor. Pencilan pada data spasial sering ditemukan dan membuat estimasi parameter menjadi bias, untuk mengatasi data yang terkontaminasi oleh pencilan digunakan suatu metode statistik yaitu regresi robust. Maka dari itu untuk mengatasi pencilan pada model SDM dapat dilakukan menggunakan metode Robust Spatial Durbin Model (RSDM).

Analisis regresi digunakan hampir pada semua bidang kehidupan sehari-hari, salah satunya pada bidang industri dan ketenagakerjaan. Pada bidang ini, beberapa permasalahan utama di masyarakat yang dipengaruhi oleh adanya efek spasial yaitu mengenai pengangguran. Pengangguran merupakan salah satu persoalan yang dialami oleh banyak negara didunia termasuk Indonesia.

Provinsi di Indonesia yang mempunyai masalah pengangguran terbuka terbanyak adalah Jawa Barat, dengan menempati urutan pertama pada februari 2019. Menurut Badan Pusat Statistik (BPS), Jawa Barat merupakan provinsi dengan jumlah penduduk besar yaitu sebanyak 49.316.712 jiwa dan mempunyai Tingkat Pengangguran Terbuka (TPT) sebesar 7,73 persen dengan jumlah angkatan kerja sebanyak 23,83 juta orang, yaitu sebanyak 21,99 juta orang adalah penduduk bekerja sedangkan sebanyak 1,84 juta orang menganggur. TPT di Provinsi Jawa Barat dipengaruhi oleh kondisi industri, selama ini Jawa Barat dikenal sebagai provinsi dengan jumlah industri yang tinggi dan itu memacu penduduk di luar Jawa Barat untuk pindah ke provinsi ini. Tujuan dari penelitian ini untuk memodelkan TPT di Provinsi Jawa Barat Tahun 2019 menggunakan metode RSDM dan mengidentifikasi faktor-faktor apa saja yang mempengaruhi TPT di Provinsi Jawa Barat Tahun 2019.

\section{B. Metodologi Penelitian}

\section{Matriks Pembobot Spasial}

Matriks pembobot spasial merupakan matriks yang menggambarkan hubungan ketetanggaan antar wilayah pengamatan. Salah satu jenis matriks pembobot spasial yaitu Queen contiguity (Persinggungan Sisi dan Sudut) yang akan dilakukan dalam penelitian ini. Matriks pembobot spasial ini mendefinisikan nilai $w_{i j}=1$ jika wilayah bersinggungan sisi dan sudut dengan wilayah lainnya, sedangkan nilai $w_{i j}=0$ jika tidak bersinggungan.

\section{Uji Efek Spasial}

Untuk mengetahui adanya efek spasial yaitu dengan dependensi spasial. Dependensi spasial menunjukkan bahwa pengamatan pada suatu wilayah bergantung pada pengamatan di wilayah lain. Untuk mengetahui adanya dependensi spasial yaitu menggunakan uji Indeks Moran dengan hipotesis sebagai berikut Yasin et al., (2020):

$H_{0}: I_{M}=0$ (Tidak terdapat autokorelasi antar spasial)

$H_{1}: I_{M} \neq 0$ (Terdapat autokorelasi antar spasial)

Statistik uji seperti pada persamaan berikut:

$Z=\frac{I_{M}-E\left(I_{M}\right)}{\sqrt{\operatorname{Var}\left(I_{M}\right)}} \sim N(0,1)$

$$
\begin{gathered}
I_{M}=\frac{n \sum_{i=1}^{n} \sum_{j=1}^{n} w_{i j}\left(x_{i}-\bar{x}\right)\left(x_{j}-\bar{x}\right)}{\sum_{i=1}^{n} \sum_{j=1}^{n} w_{i j} \sum_{i=1}^{n}\left(x_{i}-\bar{x}\right)^{2}} \\
S_{0}=\sum_{i=1}^{n} \sum_{j=1}^{n} w_{i j} \\
E\left(I_{M}\right)=I_{0}=-\frac{1}{n-1}
\end{gathered}
$$




$$
\begin{aligned}
& S_{1}=\frac{1}{2} \sum_{i \neq j}^{n}\left(w_{i j}+w_{j i}\right)^{2} \\
& \quad \operatorname{Var}\left(I_{M}\right)=\frac{n^{2} S_{1}-n S_{2}+3 S_{0}^{2}}{\left(n^{2}-1\right) S_{0}^{2}}-\left[E\left(I_{M}\right)\right]^{2} \\
& S_{2}=\sum_{i \neq j}^{n}\left(w_{i 0}+w_{0 i}\right)^{2} \\
& \quad w_{i 0}=\sum_{i=1}^{n} w_{i j} ; w_{0 i}=\sum_{j=1}^{n} w_{i j} \\
& \text { Pengambilan keputusan } H_{0} \text { ditolak jika }|Z|>Z_{\alpha / 2} \\
& \text { Spatial Durbin Model (SDM) }
\end{aligned}
$$

\section{Spatial Durbin Model (SDM)}

Menurut Anselin (1988) dalam Hakim et al., (2020) menyatakan bahwa Spatial Durbin Model (SDM) merupakan model regresi spasial yang memiliki lag spasial pada variabel respon maupun variabel prediktor. Model SDM adalah sebagai berikut:

$$
\begin{gathered}
\boldsymbol{y}=\rho \mathbf{W y}+\alpha \mathbf{1}_{n}+\boldsymbol{X} \boldsymbol{\beta}+\mathbf{W X} \boldsymbol{\theta}+\boldsymbol{\varepsilon} \\
\boldsymbol{\varepsilon} \sim N\left(0, \sigma^{2} \boldsymbol{I}_{n}\right)
\end{gathered}
$$

Atau dapat ditulis sebagai berikut:

$$
\boldsymbol{y}=\rho \mathbf{W} \mathbf{y}+\mathbf{Z} \boldsymbol{\delta}+\boldsymbol{\varepsilon}
$$

Dimana,

$\boldsymbol{y}=$ vektor variabel respon berukuran n $\mathrm{x} 1$

$\rho=$ koefisien lag spasial variabel respon $(\boldsymbol{y})$

$\mathbf{W}=$ matriks pembobot berukuran $\mathrm{n} \times \mathrm{n}$

$\boldsymbol{Z}=\left[\begin{array}{lll}\mathbf{1}_{n} & \mathbf{X} & \mathbf{W X}\end{array}\right]$

$\delta=\left[\begin{array}{lll}\alpha & \boldsymbol{\beta} & \boldsymbol{\theta}\end{array}\right]^{T}$

$\boldsymbol{\varepsilon}=$ vektor error berukuran $\mathrm{n} \times 1$

$\mathbf{1}_{n}=$ Vektor yang berisi angka 1 berukuran $\mathrm{n} \times 1$

Untuk mengestimasi parameter SDM dapat menggunakan metode Maximum Likelihood Estimation (MLE). Fungsi likelihood dibentuk melalui persamaan error $(\boldsymbol{\varepsilon})$ berdistribusi normal (Yasin et al., 2020):

$$
\begin{gathered}
\boldsymbol{y}=\rho \mathbf{W} \mathbf{y}+\mathbf{Z} \boldsymbol{\delta}+\boldsymbol{\varepsilon} \\
\boldsymbol{\varepsilon}=\mathbf{y}-\rho \mathbf{W} \mathbf{y}-\mathbf{Z} \boldsymbol{\delta} \\
\boldsymbol{\varepsilon}=(\boldsymbol{I}-\rho \mathbf{W}) \mathbf{y}-\mathbf{Z} \boldsymbol{\delta}
\end{gathered}
$$

Fungsi kepadatan peluang dari $\boldsymbol{\varepsilon}_{i}$ dengan $\boldsymbol{\varepsilon} \sim N\left(0, \sigma^{2} \boldsymbol{I}\right)$ adalah sebagai berikut:

$$
f\left(\varepsilon_{i} \mid \sigma^{2}\right)=\frac{1}{\sigma \sqrt{2 \pi}} e^{\left(-\frac{\varepsilon_{i}^{2}}{2 \sigma^{2}}\right)}
$$

Didapatkan fungsi logaritma natural untuk mengestimasi $\rho$ :

$$
l(\rho \mid y)=C-\frac{n}{2} \ln \left(\left[e_{0}-\rho e_{d}\right]^{T}\left[e_{0}-\rho e_{d}\right]\right)+\ln |\boldsymbol{I}-\rho \mathbf{W}|
$$

Dimana $C$ merupakan konstanta yang tidak bergantung pada parameter $\rho$. Besar parameter $\rho$ berada pada rentang $\frac{1}{\lambda_{\min }}<\rho<\frac{1}{\lambda_{\max }}$ dengan $\lambda$ merupakan nilai eigen dari matriks $\mathbf{W}$ yang distandarisasi.

Estimasi parameter $\boldsymbol{\delta}$ adalah

Estimasi parameter $\sigma^{2}$ adalah

$$
\widehat{\boldsymbol{\delta}}=\widehat{\boldsymbol{\delta}}_{0}-\hat{\rho} \widehat{\boldsymbol{\delta}}_{\boldsymbol{d}}
$$

$$
\widehat{\boldsymbol{\sigma}}^{2}=\frac{\left(e_{0}-\hat{\rho} e_{d}\right)^{T}\left(e_{0}-\hat{\rho} e_{d}\right)}{n}
$$

\section{Uji Kecocokan Model}

Menguji kecocokan model Spatial Durbin Model (SDM) yaitu menggunakan prosedur uji dan hipotesis sebagai berikut (Ramadani et al., 2013):

$H_{0}: \rho=\beta_{j}=\theta_{j}=0$, dengan $j=1,2,3, \ldots, k$

$H_{1}: \rho \neq 0$ atau setidaknya ada satu $\beta_{j} \neq 0, \theta_{j} \neq 0$, dengan $j=1,2,3, \ldots, k$

Statistik uji seperti pada persamaan berikut:

$$
F=\frac{\left(S S_{T}-S S_{R}\right) / k}{S S_{R} /(n-k-1)}
$$


Dengan,

$$
\begin{aligned}
& S S_{T}=\sum_{i=1}^{n}\left(y_{i}-\bar{y}\right)^{2} \\
& S S_{R}=\sum_{i=1}^{n}\left(y_{i}-\hat{y}\right)^{2} \\
& \text { Pengambilan keputusan } H_{0} \text { ditolak jika } F>F_{(\alpha, k, n-k-1)} \text { atau } P_{\text {value }}<\alpha
\end{aligned}
$$

\section{Uji Signifikansi Parameter}

Menurut Anselin (1988) dalam Ramadani et al., (2013) menguji signifikansi parameter untuk pemodelan spasial yaitu menggunakan uji Wald. Untuk parameter $\rho$ menggunakan hipotesis sebagai berikut:

$$
\begin{aligned}
& H_{0}: \rho=0 \\
& H_{1}: \rho \neq 0
\end{aligned}
$$

Statistik uji seperti pada persamaan berikut:

$\operatorname{Wald}_{\rho}=\frac{\widehat{\rho}^{2}}{\operatorname{Var}(\widehat{\rho})}$

Untuk parameter $\beta$ menggunakan hipotesis sebagai berikut :

$H_{0}: \beta_{j}=0$

$H_{1}: \beta_{j} \neq 0, j=1,2, \ldots, k$

Statistik uji seperti pada persamaan berikut:

$\operatorname{Wald}_{\beta}=\frac{{\widehat{\beta_{J}}}^{2}}{\operatorname{Var}\left(\widehat{\beta_{J}}\right)}$

Untuk parameter $\theta$ menggunakan hipotesis sebagai berikut :

$H_{0}: \theta_{j}=0$

$H_{1}: \theta_{j} \neq 0, j=1,2, \ldots, k$

Statistik uji seperti pada persamaan berikut:

Wald $_{\theta}=\frac{{\widehat{\theta_{J}}}^{2}}{\operatorname{Var}\left(\widehat{\theta_{J}}\right)}$

Dimana,

$\operatorname{Var}(\hat{\rho})=$ elemen diagonal dari matriks varians yang berkorespondensi terhadap $\rho$

$\operatorname{Var}\left(\widehat{\beta}_{I}\right)=$ elemen diagonal dari matriks varians yang berkorespondensi terhadap $\beta$

$\operatorname{Var}\left(\widehat{\theta}_{J}\right)=$ elemen diagonal dari matriks varians yang berkorespondensi terhadap $\theta$

Pengambilan keputusan adalah $H_{0}$ ditolak jika nilai Wald $>\chi_{\alpha, 1}^{2}$

\section{Ukuran Kecocokan Model}

Menentukan ukuran kecocokan model dilakukan dengan menghitung nilai koefisien determinasi $\left(\mathrm{R}^{2}\right)$ dan Mean Squared Error (MSE). Beberapa peneliti lebih banyak menggunakan nilai Adjusted $\mathrm{R}^{2}$ untuk regresi yang memiliki lebih dari 2 variabel prediktor. Dirumuskan sebagai berikut (Musyarofah et al., 2020):

$$
R_{a d j, k}^{2}=\frac{S S_{R}}{S S_{T}}=1-\frac{S S_{E} /(n-k-1)}{S S_{T} /(n-1)}
$$

Dengan,

$S S_{E}=$ Sum of squared of the residual error

$S S_{T}=$ Total sum of squared

$S S_{R}=$ Regression sum of squared

Perhitungan MSE dilakukan dengan rumus sebagai berikut (Montgomery et al., 2012):

$$
M S E=\frac{S S_{E}}{n-k-1}
$$

baik.

Jika nilai MSE semakin kecil hingga hampir nol, maka model regresi menjadi lebih

\section{Pencilan Spasial}

Untuk mendeteksi pencilan mengunakan Moran's Scatterplot, dengan rumus sebagai berikut:

$$
\begin{aligned}
(Z[f(i)]) & \times\left(\Sigma_{j}\left(w_{i j} Z[f(j)]\right)\right)<0 \\
Z_{i} & =\left(f(i)-\mu_{f}\right) / \sigma_{f} \\
P_{i} & =\left(\Sigma_{j}\left(w_{i j} Z[f(j)]\right)\right.
\end{aligned}
$$


Dimana,

$\begin{aligned} Z[f(i)] & =\text { nilai pengamatan yang distandarisasi } \\ Z[f(j)] & =\text { transpose nilai pengamatan yang distandarisasi } \\ P_{i} & =\text { nilai pengamatan yang distandarisasi dikalikan dengan matiks } \\ & \text { pembobot yang distandarisasi } \\ w_{i j} & =\text { matriks pembobot yang distandarisasi berukuran } n \times n \\ \mu_{f} & =\text { rata-rata dari nilai pengamatan } \\ \sigma_{f} & =\text { standar deviasi dari nilai pengamatan }\end{aligned}$

Jika nilai $(Z[f(i)]) \times\left(\Sigma_{j}\left(w_{i j} Z[f(j)]\right)\right)<0$, maka dapat dikatakan pencilan spasial.

\section{Robust Spatial Durbin Model (RSDM) M-estimator}

Robust Spatial Durbin Model (RSDM) digunakan ketika terdapat pencilan pada residual Spatial Durbin Model (SDM). Estimasi parameter RSDM dilakukan menggunakan Ordinary Least Square (OLS), diperoleh dengan cara meminimumkan jumlah kuadrat sisa sebagai berikut (Hakim et al., 2020):

$$
\sum \mathbf{e}_{\boldsymbol{i}}^{\mathbf{2}}=\sum\left[(I-\rho \mathbf{W}) \boldsymbol{y}_{i}-\mathbf{Z}_{1} \boldsymbol{\delta}_{1 i}-\mathbf{Z}_{2} \boldsymbol{\delta}_{2 i}-\cdots-\boldsymbol{Z}_{k} \boldsymbol{\delta}_{k i}\right]^{2}
$$

Untuk meminimumkan Persamaan (13) dapat dibedakan dari $\boldsymbol{\delta}^{T}$ :

$$
\begin{aligned}
& \frac{\partial}{\partial \boldsymbol{\delta}^{T}} \mathbf{e}^{T} \mathbf{e}=\frac{\partial}{\partial \boldsymbol{\delta}^{T}}\left[(\boldsymbol{I}-\rho \mathbf{W}) y^{T}(\boldsymbol{I}-\rho \mathbf{W}) \mathbf{y}-\mathbf{2}(\boldsymbol{I}-\rho \mathbf{W}) \mathbf{y} \boldsymbol{\delta}^{T} \boldsymbol{Z}^{T}+\boldsymbol{\delta}^{T} \boldsymbol{Z}^{T} \mathbf{Z} \boldsymbol{\delta}\right] \\
& \boldsymbol{Z}^{T} \mathbf{Z} \boldsymbol{\delta}=(\boldsymbol{I}-\rho \mathbf{W}) \boldsymbol{y} \boldsymbol{Z}^{T} \\
& \widehat{\boldsymbol{\delta}}_{O L S}=\left(\boldsymbol{Z}^{T} \boldsymbol{Z}\right)^{-1} \boldsymbol{Z}^{T}(\boldsymbol{I}-\rho \mathbf{W}) \boldsymbol{y}
\end{aligned}
$$

Untuk mendapatkan fungsi efek, Persamaan (14) dapat ditulis sebagai berikut:

$$
\widehat{\boldsymbol{\delta}}_{\text {OLS }}=\left(\boldsymbol{Z}^{\boldsymbol{T}} \boldsymbol{\psi} \boldsymbol{Z}\right)^{-1} \boldsymbol{Z}^{\boldsymbol{T}} \boldsymbol{\psi}(\boldsymbol{I}-\rho \mathbf{W}) \mathbf{y}
$$

Dari fungsi efek tersebut, fungsi pembobot dapat didefinisikan sebagai berikut:

$$
b_{i}=b\left(u_{i}\right)=\frac{\psi\left(u_{i}\right)}{u_{i}}
$$

Dimana $u_{i}$ adalah nilai residual $i$ yang telah distandarisasi terhadap perkiraan standar deviasi oleh $u_{i}=\frac{\mathbf{e}_{i}}{s}$. Sebelum mendapatkan nilai $u_{i}$, terlebih dahulu menghitung skala estimasi robust $\mathrm{s}$ dengan persamaan berikut:

$$
s=\frac{M A D}{0,6745}=\frac{\text { median } \mid \boldsymbol{\varepsilon}-\text { median }(\boldsymbol{\varepsilon}) \mid}{0,6745}
$$

Sehingga nilai $u$ dapat ditulis juga sebagai berikut:

$$
u=\frac{(I-\rho \mathbf{W}) \mathbf{y}-\mathbf{z} \widehat{\boldsymbol{\delta}}_{O L S}}{\frac{M A D}{0,6745}}
$$

Maka fungsi pembobot dapat ditulis sebagai berikut:

$$
b_{i}=b(u)=\frac{\psi\left(\frac{(I-\rho \mathbf{W}) \mathbf{y}-\mathbf{Z} \widehat{\boldsymbol{\delta}}_{O L S}}{\frac{M A D}{0,6745}}\right)}{\left(\frac{(I-\rho \mathbf{W}) \mathbf{y}-\mathbf{Z} \widehat{\boldsymbol{\delta}}_{O L S}}{\frac{M A D}{0,6745}}\right)}
$$

Dari proses pembobotan tersebut diharapkan diperoleh estimasi yang tidak bias karena fungsi efeknya telah distandarisasi. Oleh karena itu dari Persamaan (15) dapat ditulis sebagai berikut:

$$
\widehat{\boldsymbol{\delta}}_{\text {OLS }}=\left(Z^{T} \boldsymbol{B} Z\right)^{-1} Z^{T} \boldsymbol{B}(I-\rho \mathbf{W}) \mathbf{y}
$$

Dimana $\mathbf{B}$ merupakan matriks pembobot berukuran $n \times n$. Fungsi pembobot yang digunakan adalah pembobot Tukey Bisquare seperti berikut:

$$
b_{i}=\left\{\begin{array}{cc}
{\left[1-\left(\frac{u_{i}}{c}\right)^{2}\right]^{2}} & , \text { untuk }\left|u_{i}\right| \leq c \\
0 & , \text { untuk }\left|u_{i}\right|>c
\end{array}\right.
$$

Dengan, $c=4,685$ (Fox, 2002).

Dikarenakan fungsi $\boldsymbol{\psi}$ tidak linier, sehingga estimasi parameter dapat diselesaikan 
dengan Iteratively Reweighted Least Square (IRLS) (Fox, 2002). Perkiraan awal $\widehat{\boldsymbol{\delta}}^{(0)}$ adalah sebagai berikut (Hakim et al., 2020):

$$
\widehat{\boldsymbol{\delta}}^{(0)}=\left(Z^{T} Z\right)^{-1} Z^{T}(I-\rho \mathbf{W}) \mathbf{y}
$$

Perhitungan ini terus dilakukan berulang kali sehingga diperoleh nilai $\widehat{\boldsymbol{\delta}}$ yang konvergen, yaitu ketika nilai $\widehat{\boldsymbol{\delta}}^{(m+1)}$ dan $\widehat{\boldsymbol{\delta}}^{(m)}$ mendekati 0 dimana m merupakan jumlah iterasi.

\section{Hasil Penelitian dan Pembahasan}

Data yang digunakan dalam penelitian ini adalah data sekunder yang diperoleh dari Website Badan Pusat Statistik (BPS) Provinsi Jawa Barat dan Website Resmi Pemerintah Daerah Provinsi Jawa Barat. Dengan unit observasi dalam penelitian ini adalah 27 kabupaten/kota di Provinsi Jawa Barat. Berikut adalah varibel yang akan digunakan dalam penelitian ini:

$$
\begin{aligned}
& Y=\text { Tingkat Pengangguran Terbuka } \\
& X_{1}=\text { Indeks Pembangunan Manusia } \\
& X_{2}=\text { Upah Minimum Kabupaten/Kota } \\
& X_{3}=\text { Rasio Ketergantungan } \\
& X_{4}=\text { Tingkat Partisipasi Angkatan Kerja } \\
& X_{5}=\text { Tingkat Pendidikan } \\
& X_{6}=\text { Jumlah Penduduk Miskin }
\end{aligned}
$$

\section{Uji Efek Spasial}

Tabel 3.1 Hasil Pengujian Indeks Moran

\begin{tabular}{|c|c|c|}
\hline Variabel & Indeks Moran $\left(I_{M}\right)$ & $Z$ \\
\hline$Y$ & 0,41166147 & $3,219345^{*}$ \\
\hline$X_{1}$ & 0,32007245 & $2,564287^{*}$ \\
\hline$X_{2}$ & 0,75697365 & $5,689067^{*}$ \\
\hline$X_{3}$ & 0,26427599 & $2,165223^{*}$ \\
\hline$X_{4}$ & 0,15560165 & 1,387968 \\
\hline$X_{5}$ & 0,31957939 & $2,56076^{*}$ \\
\hline$X_{6}$ & $-0,09060845$ & $-0,3729622$ \\
\hline
\end{tabular}

*) signifikan pada $\alpha=5 \%$ atau $Z=1,96$

Terdapat 5 variabel yang memiliki autokorelasi antar spasial sehingga model Spatial Durbin Model (SDM) dapat dilakukan dalam penelitian ini.

\section{Spatial Durbin Model (SDM)}

Setelah diperoleh hasil terdapat autokorelasi antar spasial, maka model SDM dapat dilakukan. Asumsi SDM yaitu residual berdistribusi normal, Oleh karena itu dilakukan uji normalitas. Dari hasil perhitungan diperoleh nilai $\mathrm{P}$-value $=1$, karena $\mathrm{P}$-value lebih besar dari $(\alpha=0,05)$ sehingga disimpulkan bahwa residual berdistribusi normal.

\section{Pencilan Spasial}

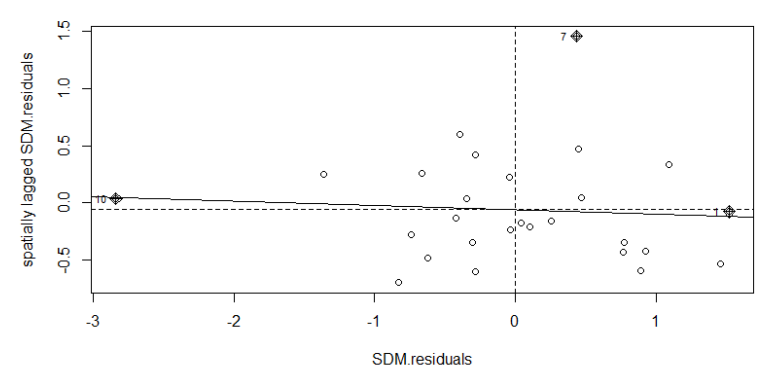

Gambar 3.1 Grafik Moran's Scatterplot 
Pada grafik diatas memperlihatkan secara visual terdapat pencilan spasial pada residual SDM, yaitu plot yang tersebar pada kuadran I (High-High) atau kanan atas, kudran II (LowHigh) atau kiri atas, dan kuadran IV (High-Low) atau kanan bawah. Terlihat bahwa residual model mempunyai 3 pengamatan yang tidak wajar, yaitu pada wilayah 1, 7, dan 10 .

\section{Robust Spatial Durbin Model (RSDM)}

Setelah melakukan uji pencilan spasial dan diperoleh hasil bahwa terdapat pencilan pada residual SDM, selanjutnya akan dilakukan uji menggunakan metode RSDM. Perhitungan RSDM melalui proses iterasi untuk mencapai nilai $\widehat{\boldsymbol{\delta}}$ konvergen $10^{-2}$, dan diperoleh model sebagai berikut:

$$
\begin{aligned}
& \hat{y}_{i}=-3,1498 \sum_{j=1}^{n} w_{i j} Y_{j}-1254347+0,04859 X_{1 i}-8,4282 \times 10^{-7} X_{2 i}-0,46529 X_{3 i} \\
& -0,35643 X_{4 i}-1,13110 X_{5 i}+0,01533 X_{6 i}+1,31280 \sum_{j=1}^{n} w_{i j} X_{1 j} \\
& +3,2631 \times 10^{-8} \sum_{j=1}^{n} w_{i j} X_{2 j}+0,67016 \sum_{j=1}^{n} w_{i j} X_{3 j}-0,43566 \sum_{j=1}^{n} w_{i j} X_{4 j} \\
& -2,93482 \sum_{j=1}^{n} w_{i j} X_{5 j}+0,01027 \sum_{j=1}^{n} w_{i j} X_{6 j}
\end{aligned}
$$

\section{Uji Kecocokan Model}

Untuk mengetahui apakah model Robust Spatial Durbin Model (RSDM) tersebut sesuai, maka digunakan uji kecocokan model. Model regresi dikatakan baik jika nilai $F>F_{0,05(6 ; 20)}$. Berdasarkan perhitungan $F=92,15763$, sedangkan $F_{0,05(6 ; 20)}=2,60$ sehingga dapat disimpulkan model RSDM telah sesuai.

\section{Uji Signifikansi Parameter}

Nilai koefisien dari Robust Spatial Durbin Model (RSDM) dapat dilihat pada Tabel (3.2) sebagai berikut:

Tabel 3.2 Uji Signifikansi parameter RSDM

\begin{tabular}{|c|c|c|}
\hline Parameter & Koefisien & Statistik Wald \\
\hline$\rho$ & $-0,31498$ & $7,47768^{*}$ \\
\hline$\beta_{1}$ & 0,04859 & 0,45203 \\
\hline$\beta_{2}$ & $-8,42821 \times 10^{-7}$ & $10,36217^{*}$ \\
\hline$\beta_{3}$ & $-0,46529$ & $85,55454^{*}$ \\
\hline$\beta_{4}$ & $-0,35643$ & $119,87540^{*}$ \\
\hline$\beta_{5}$ & $-1,13110$ & $41,06545^{*}$ \\
\hline$\beta_{6}$ & 0,01533 & $121,52693^{*}$ \\
\hline$\theta_{1}$ & 1,31279 & $47,11516^{*}$ \\
\hline$\theta_{2}$ & $3,2630 \times 10^{-8}$ & 0,01031 \\
\hline$\theta_{3}$ & $-0,67016$ & $28,79282^{*}$ \\
\hline$\theta_{4}$ & $-0,43566$ & $15,36115^{*}$ \\
\hline$\theta_{5}$ & $-2,93482$ & $64,79978^{*}$ \\
\hline$\theta_{6}$ & 0,01027 & $32,46259^{*}$ \\
\hline
\end{tabular}

*) signifikan pada $\alpha=5 \%$

Pada Tabel 3.2 untuk parameter $\rho, \beta_{2}, \beta_{3}, \beta_{4}, \beta_{5}, \beta_{6}, \theta_{1}, \theta_{3}, \theta_{4}, \theta_{5}$, dan $\theta_{6}$ hasilnya signifikan karena nilai statistik ujinya lebih besar dari $\chi_{0,05 ; 1}^{2}=3,841$. Sehingga dapat disimpulkan bahwa variabel Rasio Ketergantungan, Tingkat Partisipasi Angkatan Kerja (TPAK), Tingkat Pendidikan, Jumlah penduduk Miskin, efek spasial Tingkat Pengangguran JRS is licensed under Creative Commons Attribution- 
Terbuka (TPT), efek spasial Rasio Ketergantungan, efek spasial TPAK, efek spasial Tingkat Pendidikan, dan efek spasial Jumlah penduduk Miskin berpengaruh terhadap model.

\section{Ukuran Kecocokan Model}

Pada hasil analisis diperoleh nilai $R_{a d j, k}^{2}$ sebesar 0,9850, artinya Tingkat Pengangguran Terbuka (TPT) dipengaruhi oleh Indeks Pembangunan Manusia (IPM), Upah Minimum Kabupaten/Kota (UMK), Rasio Ketergantungan, Tingkat Partisipasti Angkatan Kerja (TPAK), Tingkat Pendidikan, dan Jumlah Penduduk Miskin yaitu sebesar 98,50\% dan sisanya 1,50\% dipengaruhi oleh faktor lain diluar model.

Kemudian nilai Mean Square Error (MSE) yang diperoleh sebesar 0,0445, nilai MSE ini mendekati 0 sehingga menunjukkan pemodelan Robust Spatial Durbin Model (RSDM) yang dibentuk merupakan model yang baik.

\section{Kesimpulan}

Berdasarkan pembahasan dalam penelitian ini, peneliti menyimpulkan beberapa hasil penelitian sebagai berikut:

1. Model Robust Spatial Durbin Model (SDM) yang diperoleh adalah:

$$
\begin{aligned}
\hat{y}_{i}= & -3,1498 \sum_{j=1}^{n} w_{i j} Y_{j}-1254347-0,46529 X_{3 i}-0,35643 X_{4 i}-1,13110 X_{5 i} \\
& +0,01533 X_{6 i}+0,67016 \sum_{j=1}^{n} w_{i j} X_{3 j}-0,43566 \sum_{j=1}^{n} w_{i j} X_{4 j} \\
& -2,93482 \sum_{j=1}^{n} w_{i j} X_{5 j}+0,01027 \sum_{j=1}^{n} w_{i j} X_{6 j}
\end{aligned}
$$

Model regresi spasial ini merupakan model yang baik untuk menjelaskan Tingkat Pengangguran terbuka (TPT) di Provinsi Jawa Barat Tahun 2019. Nilai Adjusted $\mathrm{R}^{2}$ sebesar 0,9850 yaitu $98,5 \%$ TPT dipengaruhi variabel yang ada didalam model.

2. Faktor-faktor yang berpengaruh signifikan terhadap Tingkat Pengangguran Terbuka (TPT) di Provinsi Jawa Barat adalah Rasio Ketergantungan, Tingkat Partisipasi Angkatan Kerja (TPAK), Tingkat Pendidikan, dan Jumlah penduduk Miskin.

\section{Acknowledge}

Peneliti mengucapkan terimakasih kepada Program Studi Statistika Unisba, Badan Pusat Statistika Provinsi Jawa Barat, dan Pemerintah Daerah Provinsi Jawa Barat.

\section{Daftar Pustaka}

[1] Fox, J. (2002). Robust Regression : Appendix to An S-Plus Companion to Applied Regression.

[2] Hakim, A. R., Warsito, B., \& Yasin, H. (2020). Live Expectancy Modelling using Spatial Durbin Robust Model. Journal of Physics: Conference Series.

[3] Hakim, A. R., Yasin, H., \& Rusgiyono, A. (2019). Modelling Live Expectancy In Central Java Using Spatial Durbin Model . Media Statistika.

[4] Musyarofah, H., Yasin, H., \& Tarno. (2020). Robust Spatial Autoregressive untuk pemodelan angka harapan hidup diprovinsi jawa timur. Jurnal Gaussian, 26-40.

[5] Ramadani, I. R., Rahmawati, R., \& Hoyyi, A. (2013). Analisis faktor-faktor yang mempengaruhi gizi buruk balita di Jawa Tengah dengan model Spatial Durbin Model. Jurnal Gaussian, 333-342.

[6] Yasin, H., Warsito, B., \& Hakim, A. R. (2020). REGRESI SPASIAL (Aplikasi dengan R). Pekalongan: WADE GROUP. 